\title{
PROSES MORFOLOGI \\ PADA EKONOMI BAHASA DALAM BAHASA JEPANG
}

Zainab Munqidzah (Corresponding Author)

Fakultas Bahasa dan Sastra Universitas kanjuruhan Malang

Jl. S. Supriyadi 48 Malang, Indonesia

Telepon: (0341) 801488 (ext. 341) email: -

\section{Vita Dyah Pietasari}

Fakultas Bahasa dan Sastra Universitas kanjuruhan Malang

Jl. S. Supriyadi 48 Malang, Indonesia

Telepon: (0341) 801488 (ext. 341) email: nindra_69@yahoo.com

\begin{abstract}
Abstraksi: Penggunaan bahasa tulis dan bahasa percakapan pada kenyataannya sangat berbeda. Seperti diketahui secara umum bahasa percakapan jauh lebih singkat dibandingkan dengan bahasa tulis. Pemendekan kalimat dalam berkomunikasi mempunyai tujuan untuk menghemat waktu dan energi yang keluar tanpa mengurangi makna yang ada sesuai dengan kaidah bahasa yang berlaku. Tanpa disadari masyarakat pengguna bahasa telah mengimplementasikan prinsip ekonomi dalam berkomunikasi. . Hal ini seperti yang disampaikan Verhar (1999: 85) bahwa "ekonomi bahasa adalah usaha yang dilakukan oleh pengguna bahasa untuk "menghemat" energi pada saat melakukan kegiatan berbahasa dengan menyingkat apa yang diucapkan selama hal tersebut tiidak berlawanan dengan kultur dimana bahasa tersebut digunakan".

Prinsip ekonomi yang diterapkan dalam berbahasa tidak bisa terlepas dari proses morfologi. . Hal ini dijelaskan oleh Ramlan (dalamSamsuri, 1988: 5) bahwa pada dasarnya yang dibahas dalam morfofonemik adalah perubahan fonologis yang disebabkan oleh penggabungan 2 morfem.Perubahan tersebut bisa berkaitan dengan penambahan, pengurangan, perubahan atau penggeseran fonem. penelitian ini adalah penelitian diskriptif kualitatif dengan tujuan untuk menegetahui 1) perubahan bunyi, 2) bentuk percakapan dan 3) perubahan bentuk kata kerja. hasil yang diperoleh dari penelitian ini adalah perubahan bunyi yang paling sering terjadi adalah pemendekan bentuk kata. selanjutnya bentuk percakapan yang paling banyak ditemukan adalah kata diakhir kalimat dihilangkan, perubahan bentuk kata kerja yang paling banyak ditemukan adalah katakerja bentuk Te.
\end{abstract}

Kata kunci: Ekonomi bahasa, Proses morfologi 


\section{Pendahuluan}

Penggunaan bahasa tulis dan bahasa percakapan pada kenyataannya sangat berbeda. Seperti diketahui secara umum bahasa percakapan jauh lebih singkat dibandingkan dengan bahasa tulis. Pemendekan kalimat dalam berkomunikasi mempunyai tujuan untuk menghemat waktu dan energi yang keluar tanpa mengurangi makna yang ada sesuai dengan kaidah bahasa yang berlaku. Tanpa disadari masyarakat pengguna bahasa telah mengimplementasikan prinsip ekonomi dalam berkomunikasi.

Hal ini seperti yang disampaikan Verhar (1999: 85) bahwa "ekonomi bahasa adalah usaha yang dilakukan oleh pengguna bahasa untuk "menghemat" energi pada saat melakukan kegiatan berbahasa dengan menyingkat apa yang diucapkan selama hal tersebut tiidak berlawanan dengan kultur dimana bahasa tersebut digunakan". Ek sonomi bahasa berlaku untuksemua bahasa. Termasuk bahasa Jepang. Contoh penggunaan ekonomi bahasa dalam bahasa Jepang sebagai berkut. Kata benkyou shitoku nai to itu berawal dari bennkyou shite okanakereba narimasen disingkat menjadi, benkyou shte oite wa ikenai to, disingkat lagi menjadi benkyou shtoku nai to..

Penggunaan prinsip ekonomi bahasa tidak bisa terlepas dari proses morfologi yang biasa disebut dengan proses morfofonemik. Hal ini seperti dijelaskan oleh Ramlan (dalam Samsuri, 1988: 5) bahwa pada dasarnya yang dibahas dalam morfofonemik adalah perubahan fonologis yang disebabkan oleh penggabungan 2 morfem. Perubahan tersebut bisa berkaitan dengan penambahan, pengurangan, perubahan atau pergeseran donem.

Bentuk- bentuk bahasa percakapan dalam bahasa Jepang banyak dituangkan dalamkarya sastra diantaranya adalahm manga. Bahgi pebelajar bahasa Jepang memahami prinsip- prinsip bahasa yang ada dalam bahasa percakapan adalah hal yang sangat penting. Karena, terjadinya sebuah komunikasi yang baik apabila kedua pihak bisa saling memahami apa yang disampaikan oleh lawan bicara. 


\section{Metode Penelitian}

Penelitian ini merupakan penelitian diskriptif kulitatif yang bertujuan untuk mendiskripsikan 1) perubahan bunyi, 2) bentuk percakapan dan 3) perubahan bentuk kata kerja yang ada pada dialok dari tokoh komik Konan Volume 1.

Lebih mengutamakan proses daripada hasil. Maksudnya, dalam melaksanakan pengumpulan data lebih diorientasikan pada proses. Oleh karena itu , waktu melaksanakan pengumpulan data bersifat fleksibel dan perolehan data tidak berdasarkan perencanaan atau target tertentu baik jenis atau jumlahnya.

Analisis bersifat induktif, yaitu penelitian ini tidak diarahkan untuk memperkuat atau menolak hipotesis tertentu. Karena itu paparan hasil analisis sidasarkan pada data alamiah yang terkumpul dari cerita komik Konan Volume 1.

\section{Pembahasan}

Seperti sudah diketahui sebelumnya bahwa dalam berkomunikasi tanpa disadari baik pebicara maupun pembicara melakukan penyingkatan atau pemendankan kata. Tujuannya adalah untukmenghemat waktu tanpa mengurang makna yang ingin disampaikan dalam komunikasi tersebut. Oleh karena itu dalam penggunaan bahasa percakapan cendrung lebih pendek dan simple dibandingkan dengan bahasa tulis.

Yoko Tomisaka dalam bukunya Nameraka Nihongo (2000) menjelaskan bahwa bahasa percakapan dalam bahasa Jepangterbentuk berdasarkan pada 1) perubahan bunyi, 2) bentuk percakapan dan 3) tujuan percakapan. pada penelitian ini yang dikaji adalah perunbahan bunyi dan bentuk percakapan.

\section{Perubahan Bunyi}

a. Pemendekan bunyi jumlah data yang diperoleh dari dialok tokoh- tokoh pada komik Konan Volume 1 adalah 91. Pemendekan bunyi tersebut seperti, te iru menjadi te ru, te ita menjadi t eta, te inai menjadi te nai, te ita menjadi te ta, te okumenjadi to ku, te inakatta menjadi te nakatta. Berikut ini beberapa contoh data yang telah diperoleh,

Tabel 1

\begin{tabular}{|c|c|}
\hline Bahasa tulis & $\begin{array}{c}\text { Dialok pada komik } \\
\text { Konan Volume 1 }\end{array}$ \\
\hline
\end{tabular}




\begin{tabular}{|c|c|}
\hline Bare shite irun da & Bare shiten da!! \\
\hline $\begin{array}{c}\text { Mou katte iru no } \\
\text { desu yo }\end{array}$ & $\begin{array}{c}\text { Mou katterun da } \\
\text { yo }\end{array}$ \\
\hline $\begin{array}{l}\text { Wasurete inai } \\
\text { deho- ne }\end{array}$ & $\begin{array}{c}\text { Wasurete nai } \\
\text { desho-ne }\end{array}$ \\
\hline $\begin{array}{c}\text { Tanoshimi ni shite } \\
\text { ita }\end{array}$ & $\begin{array}{c}\text { Tanoshimi ni } \\
\text { shiteta }\end{array}$ \\
\hline $\begin{array}{c}\text { Sakkaa buyamete } \\
\text { inakattara }\end{array}$ & $\begin{array}{c}\text { Sakkaa buyamete } \\
\text { nakattara }\end{array}$ \\
\hline
\end{tabular}

b. Pemendekan Bentuk Kata

Tomi saka (2000: 6) menjelaskan pemendekan bentuk kata tersebut seperti dijelaskan pada table berikut

Tabel 2

\begin{tabular}{|c|c|}
\hline Bahasa tulis & $\begin{array}{c}\text { Bahasa } \\
\text { percakapan }\end{array}$ \\
\hline --masu & Bentuk kamu \\
\hline Yomimasu & Yomu \\
\hline Masen & Nai \\
\hline Yomimasen & yomanai \\
\hline Mashita & --- ta \\
\hline Yomimashita & yonda \\
\hline Masen deshita & Nakatta \\
\hline $\begin{array}{c}\text { Yomimasen } \\
\text { deshita }\end{array}$ & yomanakatta \\
\hline -----mashou & ------ou \\
\hline De wa & $\mathrm{Ja}$ \\
\hline Yonde wa ikenai & Yonja ikenai \\
\hline
\end{tabular}

\begin{tabular}{|c|c|}
\hline $\begin{array}{c}\text { Te wa } \\
\text { Tabete wa ikenai }\end{array}$ & $\begin{array}{c}\text { Cha } \\
\text { Tabecha ikenai }\end{array}$ \\
\hline Te shimau & Chau \\
Tabete shimau & tabechau \\
\hline De shimau & Jau \\
Yonde shimau & Yonjau \\
\hline Nakereba & Naranakya \\
narimasen & tabenaranakya \\
Tabenakereba & \\
narimasen & \\
\hline
\end{tabular}

Beberapa contoh temuan yang ada pada komik Konan Volume 1

(1) Ittai dare desu ne menjadi ittai dare da ne

(2) Hera hera shite shimatte menjadi hera hera shichatte

(3) Okoranai de kudasai menjadi okoru na yo

(4) Ore ha bouya de ha arimasen menjadi ore ha boure ja nai

(5) Chotto shinichi no ie ni itte kimasu Menjad Chotto shinichi no ie ni itte Kuru

(6) Hakase no koto wo yarimashouka Menjadi Hakase no koto wo itte Yarouka 
Data yang ditemukan pada pemendekan bentuk kata kerja 251

\section{c. Perubahan bunyi tidak merubah makna}

Tomisaka (2000: 7) menjelaskan bahwaperubahan bunyi pada kata yang digunakan dalam bahasa Jepang tidakmerubah makna. pada penelitian ini ditemukan 42 data perubahan bunyi tetapi tidak merubah makna, yaitu bentuk panjang menjadi pendek seperti Pada table di bawah ini

Tabel 3

\begin{tabular}{|c|c|}
\hline Bahasa Tulis & $\begin{array}{c}\text { Bahasa } \\
\text { Percakapan }\end{array}$ \\
\hline Kawaii & kawaii \\
\hline Urusai & Uruse \\
\hline Matte & Mate \\
\hline Shimau & Chimau \\
\hline
\end{tabular}

Beberpa contoh data yang diperoleh adalah:

(1) konan san matte kudasai menjadi konan san mate yo

(2) urusai ----- uruse

(3) tabete shimau ----- tabe chimau

\section{d. Sesuatu (pesan) yang diisampaikan} oleh seseorang.

Tomisaka (2000: 9) menjelaskan untuk menyampaikan sesuatu bisa berupa pesan dari seseorang menggunakan ........ to iimasu, dalam bahasa percakapan kalimat tersebutmenjadi ......tte. Pada penelitian ini dtemukan 18 data diantaranya adalah

(1) Onna no chikara ja dekinai to iu Menjadi Onna no chikara ja

\section{Dekinaitte}

(2) Aru to itte menjadi arutte

(3) Sugata made mirareru nan to itte

Menjadi Sugata made mirareru

Nantte

\section{e. . Perubahan bunyi pada akhir kata menjadi $ん " n "$}

Tomisaka (2000: 9) menjelaskan bahawa dalam bahasa percakapan, ada beberapa bunyi akhir pada kata berubah menjadi ん"n". buny akhir terbeut adalah $ら$ り るれ ろ“ra, ri ru, re,ro” selain itu bentuk negatif ない “nai” dan penggunaan kata bantu の “ no” pada akhir kalimat serta kata bantu "no" yang menunjukkan kepemilikan.. Pada 
penelitian ini data yang ditemukan sebanyak 64. Diantaranya adalah,

(1) Naranai menjadi naran

(2) Shitanode menjadi shitande

(3) Tantei ha tsutomaranai wa yo

Menjadi tantei ha tsutomannnai wa yo

\section{f. . Perubahan kata menjadi lebih pendek}

Tomisaka (2000: 11) menjelaskan bahwa pemendekan kata dalam bahasa Jepang sering terjadi pada bahasa percakapan. Pemendekan itu bias berupa penghilangan huruf di awal kata,p di tengan dan akhir kata. Pada penelitian ini ditemukan 31 data. Penghilangan huruf di awal kata misalnya,
(1) Mattaku menjadi ttaku
(2) Sore de ha menjadi de ha

Penghilangan bunyi di tengah kata

(1) Anata menjadi anta

(2) Watashi menjadi washi

(3) Sumimasen menjadi suman

\section{Penghilangan bunyi di akhir kata}

(1) Hontou menjasdi honto

(2) Darou menjadidaro

\section{Bentuk Percakapan}

Dalam bukunya yang berjudul Nameraka

Nihongo , Tomisaka (2000: 32) menjelaskan ada 6 bentuk percakapan dalam bahasa Jepang, yaitu: 1) penghilangan kata bantu, 2) penghilangan kata, 3) akhir kalimat yang disingkat 4) pengulangan, 5) kesamaran dan 6) merubah urutan kata. Dari keenam bentuk percakapan tersebut yang tercakup dalam ekonomi bahasa adalah 5 bentuk. Hal ini karenabentuk pengulangan bukan mengurangi kata tetapimenambah jumlah kata.

\section{a. Penghilangan kata bantu}

Data yang ditemukan untuk penghilangan kata bantu sebanyak 71 . Kata bantu yang paling sering dihilangkan dalam percakapan adalah kata bantu wa yang menyertai subyek dan terletak di awal kalimatserta kata bantu ka yang terletak pada akhir kalimat yang berfungsi untuk menyatakan kalimat tersebut adalah kalimat Tanya.berikut beberapa contoh bentuk percakapan yang menghilangkan kata bantu.

(1) Goshujin wa anata desu menjadi Goshujin anata desu 
(2) Bakka no mitai menjadi bakka mitai

(3) Roku sai kara nana sai made

Menjadi roku-nana sai

(4) Ja-kore nara dou desu ka menjadi

ja-korenara do-da?

\section{b. Penghilangan kata}

Tomisaka

(2000:

menjelaskan pada bentuk percakapan ini meskipun kata dalam sebuah dialok tidak dinampakkan secara harafiah, tetapi dari penakanan kata bisa dlihat bahwa kalimat tersebut mengandung makna permohonan, perintah, larangan, sesuatu yang harus dilakukan serta menyampaikan apa yang di dengar dari orang lain. Selain intonasi dari percakapan yang bisa menentukan makna dari kalimat tersebut bisa dengan merujuk pada kalimat atau kata sebelumnya. Data yang ditemukan pada penelitian ini sebanyak 134 data. Bebarapa data tersebut adalah:

(1) Matte kudasai menjadi Matte

(2) Otegara nan to kikimashitaka menjadi Otegara nan datte

(3) Asatte iru no desu yo menjadi asatten no yo

(4) Kore wa jiko janai desu menjadi
Kore wa jiko janai

(5) Ba, baka na koto iwanaide kudasai Imenjadi Ba, baka na koto iwanaide

\section{c. Akhir kalimat yang disingkat}

Selanjutnya Tomisaka (2000: 32) menjelaskan bentuk bahasa percakapan selanjutnya adalah dengan menyingkat kata pada akhir kalimat. Misalnya douzo tabete kudasai dalam bahasa percakapan kalimat tersebut cukupdiucapkan dengan douzo.

Dalam penelitian ini bentuk percakapan seperti ini ada 174 data yang ditemukan. Berdasarkan dari analisis yang dilakukan dalam bentuk percakapan ini,nukan hanya menyingkat kata pada akhir kalimat bahkan ada yang menghilangkan kata pada akhir kalimat. Makna dari kalimat tersebut bias dipahami dengan mengacu pada kalimat sebelumnya. Selain itu dikuatkan dengan gambar yang ada pada manga (komik). Berikut ini diberikan beberapadata yang ditemukan, yaitu:

(1) Dannna sama ashi ga ..... ( mou naottenda yo) Dannna sama ashi $g a$

Asumsi kata di akhir kalimat 
tersebuut mengacu pada kalimat

sebelumnya serta dikuatkan

dengan gambar menyertai dialok

tersebut

(2) ani ga arimasu yo menjadi nani yo

\section{d. Bentuk kesamaran}

Dalam bahasa percakapan oleh

Tomisaka (2000: 35) dijelaskan dengan

penggunaan kata nan ka, de mo, tari, shi

dan to ka. Data yang ditemukan dalam

penelitian ini hanya 5. Yaitu:

(1) Uso ni kimatteru de shi

(2) Kou iu koto ka ne

(3) Koibito doushi no kenka ga genin $\mathrm{ka}$

(4) Han nin no oto to ka hen na oto toka

(5) Hakkiri to wa

\section{e. . Merubah urutan kata}

Yang dimaksud dengan merubah urutan kata pada bentuk percakapan dalam bahasa Jepang adalahmeletakkan kata tidak sesuai dengan kaidah gramatikal bahas a Jepang. Selanjutnya, Tomisaka (2000: 40) menjelaskan bahwa yang termasuk dalam merubah urutan kata adalah 1) Meletakkan kata tanya di depan kalimat, 2) Meletakkan kata yang mengungkapkan perasaan di depan kalimat, 3) Kata yang ada di depan kalimat merupakan akibat, selanjutnya kata yang di akhir kalimat menunjukkan sebab, 4) Pembicaraan sebelumnya mengajak lawan bicara untuk menjadi bagian dari aktivitas yang dilakukan,

Berdasarkan dari teori yang disampaikan olehTomisaka dan sumber data dari penelitian ini ditemukan 53 data. Beberapa data tersebut diantaranya adalah:

(1) kono attakai no, nani yo menjadi nani yo. Kono attakai no!?

(2) Ran, okaettaka? Menjadi okaettaka, ran?

(3) kono kungaki ga ni ki wo tsukero menjadi ki wo tsukero,kono kungaki

3. Perubahan Bentuk Kata Kerja Dalam Bahasa Jepang

Sutedi (2008: 48-61) menjelaskan secara garis besar ada 6 macam perubahan kata kerja. Yaitu: 1) 未然形 'Mizenkei', 2) 連用形'renyoukei', 3) 終止 形“shuushikei', 4) 連体刑” rentaikei”, 5) かていけい

仮定形 “kateikei”, 6) 命令形 “meireikei 
Dibawah ini akan diuraikan hasil temuan yang diperoleh dari data yang telah dianalisis.

\section{a. 未然形'Mizenkei’}

Perubahan bentuk kata kerja ini menunjukkan bahwa aktifitas belum berlangsung. Perubahan bentuk kata kerja ini meliputi Bentuk menyangkal (〜ない), maksud (おう、よう)、 bentuk pasif (れる・られる)、 bentuk menyuruh (せる・させる). Data yang ditemukan untuk 未然形“mizenkei” pada komik “manga” 234 data. Yang terdiri dari bentuk menyangkal 138, bentuk maksud 28, bentuk pasif 50 dan bentuk shieki 18.

\section{B. 連用形'Renyoukei'}

Peruhan bentuk kata kerja kelompok sopan bentuk sopan (ます), bentuk sambung $(\sim \tau)$, bentuk lampau （〜た）, bentuk kata kerja mempunyai makna hasrat/ keinginan( たい). Data yang ditemukan sebanyak 799. Dengan uraian berikut ini,

bentuk sopan (ます) sebanyak 128 bentuk sambung $\quad(\sim \tau)$ sebanyak 376 bentuk lampau（〜た） sebanyak 240 bentuk kata kerja mempunyai makna hasrat/ keinginan( たい) sebanyak 18

\section{C. 終止形'Shuushikei'}

Perubahan bentuk kata kerja diakhir kalimat. Yang masuk dalam kelompok ini adalah kata kerja bentuk kamus. Perubahan bentuk kata kerja ini biasa digunakan dalam bentuk bahasa percakapan. Data yang ditemukan sebanyak 100

\section{D. 連体刑 “Rentaikei”}

Bentuk kamus yang digunakan untuk modifikator. Misalnya: bentuk kemampuan ( bentuk kamus + koto ga dekiru), bentuk larangan (bentuk kamus + na), bentuk kamus + mae ni

\section{かていけい}

E. 仮定形 “Kateikei”

Bentuk pengandaian, perubahan bentuk kata kerja ini meliputi tara, nara, ba, to. Data yang ditemukan sebanyak 54

F) 命令形 “meireikei”. 
命令形 “meireikei”. Bentuk kata

kerja ini bermakna memerintah, data yang ditemukan sebanyak 54 ..

\section{Kesimpulan}

Berdasarkan seluruh paparan di atas bisa diambil beberapakesimpulan dalam peneltitian ini. Kesimpulan tersebut adalah

1. Penghilangan kata sandang san saat tokoh yang ada dalam komik konan volume 1menyebut nama tokoh yang lain.

2. Dalam satu dialok ditemukan beberpa perubahan bunyi dan bentuk percakapan

3. Untuk perubahan bunyi data yang banyak ditemukan adalah pemendekan bentuk kata

4. Untuk bentuk percakapan data yang banyak ditemukan adalah penyingkatan kata pada akhir kalimat

5. Perubahan bentukkata kerja yang paling banyak ditemukan adalah bentuk Te

6. Tetapa memegang kaidah kesantunan berbahasa, meskipun dalam bentuk percakapan. dbuktikan dengan temuan bentuk perintah non formal hanya 54
7. Orang Jepang dalam berkomunikasi dalam bahasa percakpan lebih suka menghilangkan kata di akhir kalimat.

8. Perbedaan yang sangat mencolok antara bahasa tulis dan bahasa percakapan yaitu dalam bahasa tulis penggunaan partikel dan susunan kalimat sangat di perhatikan sedangkan, dalam bahasa percakapan hal tersebut diabaikan. 
Aoyama, G. 1994. コナン. 東京：小学館

Samsuri. 1988. Morfologi Dan Pembentukan Kata. Jakarta: P2LPTK

Sutedi, D. 2008. Dasar-Dasar Bahasa Linguistik Jepang. Bandung: Humanoria Utama Perss

Tomisaka, Y. 1997. なめらか 日本語 会話 Successful Communication in

Japanese. Tokyou: アルク

Verhaar, J. W. M. 1996. Asas-Asas Linguistik Umum. Yogyakarta: Gajah Mada University Pres 